\title{
VIOLÊNCIA CONTRA A MULHER: EXPERIÊNCIA DE PROFISSIONAIS FACILITADORES DE UM GRUPO REFLEXIVO DE HOMENS
}

\author{
Felipe Zeferino Pê \\ Railda Sabino Fernandes Alves \\ Universidade Estadual da Paraíba, Campina Grande-PB, Brasil \\ Clarissa Paranhos Guedes \\ Marceane de Azevedo Silva \\ Marcia Batista Bastos \\ Juizado de Violência Doméstica e Familiar Contra Mulher, Campina Grande-PB, Brasil
}

\section{RESUMO}

A violência contra a mulher é uma das maiores causas de homicídio no Brasil. Como alternativa de combate surgem os grupos reflexivos de homens. O objetivo deste artigo é descrever a experiência de uma equipe multiprofissional na formação de um grupo reflexivo de homens, realizado num Juizado de Violência Doméstica e Familiar Contra Mulher. O grupo formado por nove homens, teve cinco encontros quinzenais, nos quais foram trabalhados: a violência contra mulher, o papel da justiça frente à violência doméstica e familiar, consciência emocional e masculinidades, resolução de conflitos e a Lei Maria da Penha. As conclusões apontam grande adesão dos homens ao grupo, mudanças significativas na compreensão do problema da violência, além de mudanças em seus comportamentos.

Palavras-chave: Homens; Masculinidade; Estudos de Gênero; Violência contra mulher.

\section{VIOLENCE AGAINST WOMEN: THE EXPERIENCE OF PROFESSIONAL FACILITATORS OF A REFLECTIVE GROUP OF MEN}

\begin{abstract}
Violence against women is one of the greatest causes of homicide in Brazil. As an alternative for combating this, reflective groups of men emerge. The purpose of this article is to describe the experience of a multi-professional team in forming a reflective group of men, held in a Court of Domestic and Family Violence Against Women. The group formed by nine men had five biweekly meetings in which they discussed: violence against women, the role of justice in the face of domestic and family violence, emotional and masculinity awareness, conflict resolution, and the Maria da Penha Law. The conclusions point to a
\end{abstract}

Pê et al. (2022). Violência contra a mulher: experiência de profissionais facilitadores de um grupo reflexivo de homens. https://doi.org/10.32467/issn.2175-3628v23n1a8 
great commitment of the men to the group, significant changes in the understanding of the problem of violence, besides changes in the behavior of the men.

Keywords: Men; Masculinity; Studies of Gender; Violence against women.

\section{VIOLENCIA CONTRA LA MUJER: EXPERIENCIA DE PROFESIONALES FACILITADORES DE UN GRUPO REFLEXIVO DE HOMBRES}

\section{RESUMEN}

La violencia contra la mujer es una de las mayores causas de homicidio en Brasil. Como una de las alternativas para contrarrestar el problema surgieron los grupos reflexivos de homens. El objetivo de este artículo es describir la experiencia de un equipo multiprofesional en actuación en un grupo reflexivo de homens, realizado en un Juzgado de violencia domiciliaria y familiar contra mujeres. El grupo fue formado por nueve hombres, tuvo cinco encuentros quincenales, en los cuales fueron trabajados: la violencia contra la mujer, el papel de la justicia frente a la violencia domiciliaria y familiar, la consciencia emocional y masculinidades, resolución de conflictos y la Ley Maria da Penha. Las conclusiones apuntan gran adhesión de los hombres al grupo, mudanzas significativas en la comprensión del problema de la violencia, además de mudanzas en sus comportamientos.

Palabras clave: Hombres; Masculinidad; Estudios de Género; Violencia contra mujer.

A violência contra a mulher apresenta dados preocupantes, sendo uma das maiores causas de homicídio no Brasil. Em 2018, dados do Instituto de Pesquisa Econômica Aplicada- IPEA apontaram que 4.519 mulheres foram assassinadas, o que corresponde a uma taxa de 4,3 homicídios para cada 100 mil habitantes do sexo feminino (Cerqueira et al., 2020). Já o Fórum Brasileiro de Segurança Pública (2020) levantou dados a respeito da violência doméstica durante o período da pandemia da Covid-19 (de março a maio de 2020) no Brasil e comparou com os do mesmo período do ano anterior (março a maio de 2019). Esse levantamento apontou uma redução de uma série de crimes contra as mulheres em diversos estados do Brasil. Em relação aos registros de lesão corporal dolosa, por exemplo, em todas as Unidades da Federação houve uma redução de 27,2 \% em relação aos dados do mesmo período de 2019, sendo Maranhão (84,6\%), Rio de Janeiro (40,2\%) e Ceará (26\%) os estados com maiores quedas.

Também houve uma redução do número de medidas protetivas de urgência entre março e maio de 2020, em relação ao mesmo período de 2019. No estado de São Paulo houve queda de $11,6 \%$ (passando de 17.539 para 15.502), por exemplo. No Pará as medidas protetivas de urgência caíram 12, 5\% (de 1.965 para 1.719), no Rio de Janeiro 30,1\% (de 7.706 para 5.385), e no Acre 30,7\% (de 434 para 289) (Fórum Brasileiro de Segurança Pública, 2020). Contudo, a violência letal contra mulheres aumentou em relação ao mesmo período acima citado, indicando um crescimento dos índices de feminicídio e/ou homicídios em diversos estados brasileiros.

Pê et al. (2022). Violência contra a mulher: experiência de profissionais facilitadores de um grupo reflexivo de homens. https://doi.org/10.32467/issn.2175-3628v23n1a8 
Os crimes registrados como feminicídio aumentaram 2,2\% em 2020 (março a maio) em comparação com os registros do período de 2019 (março a maio), passando de 185 para 189 casos. Já os homicídios dolosos aumentaram 7,1\%, crescendo de 127 para 136 casos. O levantamento analisou o contraste entre o aumento nos dados da violência letal e a queda de registros de lesão corporal dolosa, bem como a redução de medidas protetivas de urgência. Observou-se que esse contraste pode revelar que durante o período da Pandemia de Covid19 houve um acesso limitado aos canais de denúncia e aos serviços de proteção, o que poderia ter ocasionado a diminuição dos registros de crimes contra mulheres; e, consequentemente, a redução das concessões das medidas protetivas e o aumento do índice de feminicídios e/ou homicídios (Fórum Brasileiro de Segurança Pública, 2020).

Esses dados demonstram a importância das políticas públicas voltadas para a diminuição da incidência e reincidência de casos de violência contra a mulher. A maior conquista, no Brasil, quanto ao combate à violência contra a mulher foi estabelecida em 2006, quando promulgada a Lei $n^{\circ} 11.340$ conhecida como Lei Maria da Penha, em homenagem a Maria da Penha Fernandes (Lei $\left.n^{\circ} 11.340,2006\right)$. Ela representou um marco legislativo no país ao possibilitar novas formas de conduzir, punir e gerenciar situações de violência de gênero. No entanto, os números crescentes de feminicídio, mostrados anteriormente, indicam a necessidade de ampliar a discussão da violência contra a mulher no Brasil.

Medrado et al. (2011) apontam que a maioria dos direcionamentos dessa Lei se restringiram exclusivamente ao corpo da mulher e à sua experiência como tal, considerando os homens apenas no papel de agressores, ou seja, priorizando uma visão de violência de sexo. Esses autores alertam sobre a necessidade de questionar a forma como os homens são abordados pela Lei de modo a encontrar outras possibilidades de atendimentos que não sejam apenas de caráter punitivo.

Visando a incluir os homens nos dispositivos que combatem a violência contra a mulher surgiu, por iniciativa de alguns Juizados, o grupo reflexivo de homens. O primeiro projeto no Brasil que propôs a fomentação de grupos de homens, autores de violência contra mulher com ações socioeducativas, foi implantado no ano de 2004, em Blumenau, através do Programa de Prevenção e Combate à Violência Doméstica e Intrafamiliar (Bortoli \& Zucco, 2016).

Desde então, outras iniciativas vêm se espalhando pelo Brasil. Um mapeamento realizado em 2020 pela Coordenadoria Estadual da Mulher em Situação de Violência Doméstica e Familiar de Santa Catarina em parceria com o Grupo de Pesquisa Margens da Universidade Federal de Santa Catarina apontou que existem 312 iniciativas, programas ou grupos para homens autores de violência contra mulheres no país. Estas inciativas/grupos estão espalhadas por todas as regiões do Brasil: 126 na região sul, 65 na região sudeste, 54 na região nordeste, 42 na região centro-oeste e 25 na região norte (Beiras et al., 2020). Dentre estas inciativas está situada a experiência com grupos de homens do Poder Judiciário da Paraíba, e é sobre esta experiência que se debruça esse artigo.

Nesse sentido este artigo tem como objetivo relatar uma experiência de profissionais facilitadores de um grupo reflexivo de homens. Esse relato é fruto de nossa experiência no grupo reflexivo de homens realizado numa instituição do Juizado de Violência Doméstica e Familiar Contra Mulher de uma cidade do interior do estado da Paraíba. O objetivo do projeto desenvolvido no referido Juizado é prevenir e reduzir a reincidência da violência

Pê et al. (2022). Violência contra a mulher: experiência de profissionais facilitadores de um grupo reflexivo de homens. https://doi.org/10.32467/issn.2175-3628v23n1a8 
doméstica e familiar contra a mulher. Além disso, busca promover um ambiente reflexivo, socioeducativo e responsabilizante, que possibilite o desenvolvimento individual e grupal dos processos de socialização que tenham como base a equidade de gênero, a formação de novas masculinidades e a construção de novas formas de resolução dos conflitos.

Para compreender um pouco mais sobre o conceito das masculinidades, tão importante na metodologia dos grupos reflexivos, torna-se fundamental primeiro compreender o conceito de gênero. Segundo Scott (1989), estudar gênero requer compreender não só as experiências masculinas e femininas, mas, também buscar entender como as relações sociais influenciam às práticas de gênero. Para tanto, é necessário entendê-lo com uma categoria de análise, que busca compreender os fenômenos de gênero para além das diferenças sexuais, investigando as representações ou os sentidos produzidos por intermédio dessas diferenças.

A partir dos estudos de gênero, surgiu o estudo das masculinidades. Segundo Connell (1995, p. 188) a masculinidade é uma "[...] configuração de prática em torno da posição dos homens na estrutura das relações de gênero". Essa configuração de prática é uma forma de entender as masculinidades por meio daquilo que as pessoas realmente fazem e não mediante o que se espera ou se imagina que façam. Essas práticas, vivenciadas no dia a dia, repercutem nas experiências, sejam elas pessoais, físicas ou culturais. As masculinidades são construídas e reconstruídas pela história da cultura, por isso são dependentes das relações de poder existentes nesse processo histórico. Dessa forma, discorrer sobre masculinidades é apontar que elas não são realidades imutáveis, objetivas e impossíveis de serem modificadas, devendo ser vistas como construções fundamentadas em processos dialéticos que estão em constante alteração. Nesse sentido, observando esse processo dialético de transformação do masculino, o trabalho do grupo reflexivo pode contribuir com a transformação e reconstrução das masculinidades, visando a diminuição da violência contra mulher. Observando essas potencialidades do grupo reflexivo realizamos encontros quinzenais, que serão descritos e analisados no presente estudo.

\section{MÉTODO}

Trata-se de estudo descritivo e exploratório, caracterizado como um relato de experiência, e atendeu a todas as etapas relativas aos procedimentos éticos em pesquisas que envolvem seres humanos, prescritos na Resolução $N^{\circ}$ 510/2016 do Conselho Nacional de Saúde. Aprovado pelo Comitê de Ética e registrado com o número 16493219.1.0000.5187.

O objetivo deste artigo é descrever uma experiência de grupo reflexivo de homens. Esse relato tem por base nossa experiência como facilitadores no grupo reflexivo de homens realizado numa instituição do Juizado de Violência Doméstica e Familiar Contra Mulher de uma cidade do interior do estado da Paraíba. O referido grupo ocorre com frequência semestral e é organizado pela equipe multiprofissional permanente do Juizado, formado por duas psicólogas e uma assistente social. E para este relato de experiência contou com um psicólogo convidado, estudante do Mestrado de Psicologia da Saúde da Universidade Estadual da Paraíba.

Pê et al. (2022). Violência contra a mulher: experiência de profissionais facilitadores de um grupo reflexivo de homens. https://doi.org/10.32467/issn.2175-3628v23n1a8 
A metodologia do grupo tem um enfoque construtivista-narrativista com perspectiva de gênero. Esse enfoque busca compreender a construção da subjetividade individual e sua relação com aspectos sociais e políticos, considerando o processo dialético entre o social e o individual, tendo como base os enfoques pró-feministas e as teorias de gênero (Antezana, 2012). Além disso, uma das referências fundamentais que orientou a elaboração dos encontros foi a metodologia de grupos reflexivos produzida por Beiras e Bronz (2016). Contudo, apesar de ter como referência esse método, a metodologia proposta foi adaptada pela equipe multidisciplinar para contemplar a demanda da instituição.

$\mathrm{Na}$ experiência relatada participaram do grupo nove homens acusados de violência contra a mulher. A idade variou de 21 a 55 anos. Quanto à escolaridade seis tinham Ensino fundamental incompleto e três o Ensino médio completo. Quanto à atividade laboral seis eram trabalhadores informais, dois autônomos e um desempregado. A renda variou de um a três salários-mínimos. As sessões do grupo tiveram periodicidade quinzenal, com duração de três horas.

Ao todo foram realizados cinco encontros, nos quais trabalhamos temas como: a violência contra mulher, o papel da justiça frente à violência doméstica e familiar, consciência emocional e masculinidades, resolução de conflitos e a Lei Maria da Penha. Antes do primeiro encontro, por meio de uma entrevista, foram selecionados os participantes observando os critérios de contraindicação (critérios de exclusão definidos pelo próprio Juizado da Paraíba), vetando a participação de: autores de crimes sexual, homicídio e tentativa de homicídio; usuário abusivo de substâncias psicoativas; portador de transtornos psiquiátricos graves; autor de crimes dolosos contra a vida; homens que estivessem respondendo processos por outros crimes, além da violência doméstica. Cabe ressaltar que esses critérios são definidos pelo projeto estratégico do grupo do Juizado de Violência Doméstica e Familiar Contra Mulher da Paraíba, planejado e escrito pela sua equipe multidisciplinar.

Vale destacar que as diretrizes para Grupos Reflexivos (Beiras \& Bronz, 2016) sugerem que as atividades aconteçam em, no mínimo, doze encontros. A decisão de realizarmos apenas cinco encontros se justificou pela necessidade de aumentar a oferta de grupos e, também, pela situação socioeconômica dos homens, caracterizada pelo subemprego, e por possíveis consequências (perda de renda e demissão) de deixar de trabalhar para frequentar as reuniões.

\section{RESUltados E DiscuSSÃo}

\section{REUNIÃO DE PLANEJAMENTO}

No planejamento alinhamos nossas ações considerando que para além de organizar ou discutir temáticas, seria necessário entender as vivências que atravessam a história de cada participante, compreender sua construção social e de gênero, conhecer a realidade da violência que o conduziu ao grupo, como elementos essenciais para pensar cada encontro e desenvolver as temáticas necessárias. Conversamos, também sobre a proposta do grupo reflexivo do Juizado: seus objetivos, seu público, os procedimentos e técnicas realizadas.

Pê et al. (2022). Violência contra a mulher: experiência de profissionais facilitadores de um grupo reflexivo de homens. https://doi.org/10.32467/issn.2175-3628v23n1a8 
Revisamos as principais temáticas discutidas em outros grupos já realizados e concluídos no Juizado. Cabe ressaltar que o grupo é pensado e organizado a partir daquilo que os homens trazem, portanto, temas e técnicas utilizadas em cada encontro dependem do perfil do grupo.

Refletimos nesse planejamento que qualquer percepção de masculinidade é construída diariamente e através desse processo podemos conceber várias possibilidades de ser homem. Segundo Thürler e Medrado (2020), as masculinidades contemplam as diferentes experiências masculinas e as diversas versões da masculinidade. Portanto, a masculinidade é definida socialmente de várias formas, existindo entre elas diversas relações de poder. Dessa maneira, conhecer as histórias e experiências desses homens poderia auxiliar a reflexão sobre a construção de masculinidades, as relações de poder implicadas nesse processo e, a partir disso, refletir junto com eles sobre a violência que cometeram e/ou vivenciaram.

No trabalho com homens que cometeram violência nossa conduta profissional é desafiada ao máximo e, portanto, requer que estejamos atentos para ética profissional que assumimos - na psicologia e no serviço social - a fim de resguardar o respeito aos membros do grupo, respeitando suas opiniões ou posicionamentos, evitando julgamentos. Nesse sentido, cabe situar um dos nossos mais importantes posicionamentos: não trabalharmos sob a ótica de agressores e olharmos para cada homem como sujeitos que possuem direitos e que constroem e construíram as marcas de suas masculinidades a partir de uma dada realidade social, histórica e cultural. Sem perder de vista que os homens que cometem ou cometeram uma violência contra mulher também vivenciam, sofrem ou são influenciados por essa situação de violência. Nessa perspectiva, precisamos pensar que a violência de gênero engloba uma rede de processos multidirecionais, que envolve em sua trama sujeitos como homens, mulheres, e aspectos como as incidências e resistências da violência (Granja \& Medrado, 2009).

Assim, para podermos trabalhar mudanças necessárias, é preciso compreender que todas essas práticas de gênero, violentas ou não, são construções e como tal podem ser modificadas. Scott (1989) aponta que, para produzir mudanças nas relações de gênero, devemos buscar superar noções unificadas, coerentes e centralizadas, buscando refletir sobre as forças que fazem parte das relações de poder e que influenciam as relações sociais. Durante o planejamento inicial elegemos trabalhar as relações dos homens com suas companheiras, a fim de compreender como estavam fundamentadas para, a partir de então, trabalhar a ressignificação dessas situações que poderiam ter contribuído para a violência.

\section{PRIMEIRO ENCONTRO}

O primeiro encontro era fundamental para construir e planejar os demais. Antes de iniciar as apresentações, ressaltamos que o grupo reflexivo tem como um dos objetivos proporcionar um espaço de escuta, de acolhimento e de confiança. Beiras e Bronz (2016) apontam que um dos fundamentos nos encontros reflexivos é o respeito pela diversidade de vozes, cabendo ao facilitador garantir que esse princípio esteja em cada encontro, pois, através dele é que surge a abertura de novos significados. As mudanças que almejamos no grupo se dão através da ressignificação das experiências, principalmente porque é na

Pê et al. (2022). Violência contra a mulher: experiência de profissionais facilitadores de um grupo reflexivo de homens. https://doi.org/10.32467/issn.2175-3628v23n1a8 
linguagem que nos constituímos, por isso é tão importante o respeito à diversidade de falas do grupo.

Logo após demos início as nossas apresentações de modo informal, a fim de minimizar a ideia de punição e estimular a participação criativa do grupo. Entregamos para cada homem um crachá, pedimos que eles colocassem nele seu nome e desenhassem algo que tinha a ver com eles, seja algo do seu trabalho, ou algo que gostassem. Tínhamos conhecimento de que dois participantes não sabiam escrever, por isso oferecemos ajuda para aqueles que desejassem, de modo a diminuir possíveis constrangimentos.

A partir do momento da produção dos crachás, os homens passaram a interagir e conversar. Na chegada eles estavam enrijecidos, como se estivessem desconfiados ou constrangidos de estarem ali. No entanto, depois que nos apresentamos e começamos a produzir os crachás sentimos que eles estavam mais à vontade naquele espaço. Outro fator que ajudou a esse momento quebra-gelo foi um pequeno lanche que oferecemos, o qual foi seguido por brincadeiras e risadas.

A continuação, iniciamos as apresentações. Pedimos que falassem sobre o seu crachá e nos contassem, se possível, algo sobre si. Em cada apresentação conhecíamos algo curioso sobre cada participante, isso trazia leveza e bom humor para o grupo. No entanto, ao contarem sobre o porquê de estarem ali, sobre a história de violência que marcava suas vidas, a tristeza de alguns, o medo, os anseios, raiva e sentimento de revolta em outros, apareceram. Em meio aos aspectos negativos daquelas vivências, duas frases foram ressaltadas por eles: "estavam ali para recomeçar", e "preferiam esquecer".

Beiras e Bronz (2016) acreditam que há uma correlação entre a forma que falamos das coisas e as ações que temos frente a elas. Os autores apontam que a vivência do grupo reflexivo permite, a partir de um lugar socialmente definido, que diferentes descrições sobre como nos relacionamos possam ser expostas e confrontadas, através desse processo surgem novas descrições sobre as coisas e novas formas de nos relacionarmos frente a elas. Dessa forma, o espaço de fala era fundamental e cada homem foi partilhando, ao seu modo, sobre si ou sobre aquilo que vivenciou.

As palavras foram ganhando cores e surgiram muitos sentimentos durante essa partilha. Os participantes foram apoiando uns aos outros, principalmente, quando falaram sobre coisas difíceis que viveram ou estavam vivendo. As narrativas demonstravam um sofrimento enorme, o que nos levou a refletir sobre como a violência contra mulher afetava não só a vida delas, mas a vida desses homens, e a de todos que estavam ao seu redor. Sentíamos como a violência é um fenômeno complexo que se instaura na vida e afeta a construção da subjetividade de todos.

Cabe ressaltar que, ao pensarmos a violência contra mulher como algo que afeta também a vida dos homens - inclusive daqueles que cometeram a violência - não pretendemos desvalorizar as violências históricas vivenciadas pelas mulheres. Não temos a intenção de desconsiderar que há particularidades em cada tipo de violência que devem ser investigadas e examinadas, tampouco, desresponsabilizar os homens pelos seus atos de violência contra a mulher. Contudo, como aponta Lima (2008), cabe refletir que homens agressores não existem intrinsicamente. A violência faz parte de um processo que depende de um conjunto de fatores sociais que a produz e torna possível sua existência. Situações de violência contra mulher são constituídas por homens, mulheres, leis, relações de gênero,

Pê et al. (2022). Violência contra a mulher: experiência de profissionais facilitadores de um grupo reflexivo de homens. https://doi.org/10.32467/issn.2175-3628v23n1a8 
enfim, várias condições e diversos elementos, os quais indicam que não se pode pensá-la de maneira simplista.

No entanto, a representação de agressor existe e, por vezes, persiste. MartínezMoreno (2017) frisou que o judiciário brasileiro oferece apenas dois lugares para representar os sujeitos que vivenciaram a violência: o de agressor ou o de vítima. Lima (2019), por sua vez, aponta que através da linguagem, isto é, da colocação do fato em discurso e interações durante o grupo reflexivo, esses lugares de agressor e vítima podem ser descristalizados. Contudo, os homens que ocupam o lugar de agressor pretendem sair desse lugar, para tanto precisam mostrar que não são culpáveis. Essa ação poderia explicar por que os homens durante os primeiros encontros de grupos reflexivos tendem a negar as acusações e afirmar veementemente que são inocentes (Martínez-Moreno, 2017).

Esse sentimento de inocência é acompanhado do sentimento de injustiça. Os homens do nosso grupo, por exemplo, falaram que se sentiam injustiçados frente ao processo judicial ao qual estavam submetidos. A maioria, ao contar sobre o porquê de estar ali, relembrou o acontecido com sentimentos de raiva e tristeza, e discordância das acusações feitas a si. Em outros estudos sobre grupos reflexivos esses sentimentos relacionados à injustiça também surgiram (Habka, 2018; Moreira \& Tomaz, 2020), na ocasião, ligados à obrigatoriedade de participar de um grupo reflexivo. No nosso, porém, os homens não relataram nenhuma oposição quanto à intimação para participação dos encontros.

Ao final do primeiro encontro, construímos um contrato com regras para o melhor funcionamento do grupo, como horário, duração, tolerância a atrasos. Após o encontro, nossa equipe avaliou e discutiu sobre o que fora vivenciado e, a partir disso, planejamos a próxima reunião. Vimos que, poderíamos trabalhar diversos temas surgidos nas falas dos homens, no entanto, pela escassez do tempo para realizar os encontros, não conseguiríamos abordá-los em totalidade. Por esse motivo, tentamos selecionar os principais e modificar o planejamento caso fosse surgindo outro tema mais emergente durante os encontros. Desse modo, decidimos trabalhar o papel da justiça e refletir um pouco mais sobre a violência contra mulher.

\section{SEGUNDO ENCONTRO}

Iniciamos com uma conversa informal, através da qual um dos homens relatou que por conta de um problema de saúde não pôde mais trabalhar, deixando de ganhar o dinheiro que sustentava sua família. Sua companheira começou a reclamar, passou a não querer manter relações sexuais e afetivas com ele e saiu de casa. Ele nos contou que não aceitou o término e que a procurou diversas vezes para reatar. No entanto, sua companheira recusava tais pedidos. Ele disse que, quando bebia a procurava e, por conta do ciúme, a ameaçava até de morte. Demonstrando insatisfação e, ao mesmo tempo, um grande afeto por sua excompanheira, ele apontou que não soube lidar com a separação e não soube como reconquistá-la. Finalizou falando que tinha se arrependido e reconhecendo o erro.

Os outros homens lhe disseram que ele precisava seguir em frente. Esse momento nos marcou, pois, entre todos os homens, ele foi o único a revelar que desejava retomar o relacionamento, mas não sabia como fazer isso. Percebemos que nosso papel de facilitadores implicava em respeitar o sentimento que aquele homem tinha por sua ex-

Pê et al. (2022). Violência contra a mulher: experiência de profissionais facilitadores de um grupo reflexivo de homens. https://doi.org/10.32467/issn.2175-3628v23n1a8 
mulher, já que, apesar de tudo, aquele sentimento que carregava consigo não poderia ser excluído e nem esquecido. Essa experiência nos fez refletir sobre a importância do acolhimento realizado durante o grupo reflexivo, permitindo que os homens possam falar sobre seus sofrimentos e contradições.

Muitas vezes, nossa construção de gênero tenta excluir ou ocultar a fragilidade dos homens em diversos aspectos emocionais, fazendo com que a demonstração de sentimentos e seus sofrimentos seja vista como algo negativo para as masculinidades. Thürler e Medrado (2020) apontam que no regime de controle de gênero a sensibilidade foi atribuída à suposta natureza feminina, o homem não estaria inclinado a mostrar seus sentimentos e emoções, pois sua natureza masculina estaria ligada a outros atributos como o domínio e a força física.

Gutiérrez (2015) comenta que o silêncio emocional foi uma das características mais importantes para construção das masculinidades e com ela veio a negação da existência da dor e do sofrimento. Nesse sentido, ao sofrer por conta do término de um relacionamento, por exemplo, o homem evita demonstrar suas emoções e a procurar alternativas para lidar com essa situação. Ademais, não há espaços disponíveis para que esse homem possa expressar suas emoções e sentimentos, e, quando o faz, pode ser repreendido por não se comportar como deveria, ficando preso aos papéis sociais tradicionais (Aguiar, 2009). Ao mesmo tempo são encorajados a expressar o sentimento de raiva, o que dificulta o controle de suas emoções e fortalece o desenvolvimento de comportamentos violentos como forma de se expressarem.

Além da escuta desse homem, trabalhamos outras questões que surgiram como demanda na primeira reunião, por exemplo, os sentimentos de injustiça citados pela maioria deles. Para tanto, propusemos um júri simulado no qual os homens puderam estar na posição de advogados de defesa, promotores e juiz. Eles trabalharam em grupo para tentar analisar uma situação de violência contra mulher que ocorreu em um reality show. $\mathrm{Na}$ simulação eles puderam perceber a posição da vítima, do acusado, e daquele que deve deferir o julgamento. No final, eles relataram as dificuldades em analisar e julgar alguém, e ainda, concluíram que a vítima de uma forma ou de outra foi lesada de alguma maneira com o ocorrido.

Alguns homens, falaram sobre a importância de reconhecer o sofrimento sentido pela mulher em determinadas situações. Isso foi marcante para nossa equipe, porque no primeiro encontro os homens falaram da violência apenas pela ótica deles, e a partir dessa experiência, eles puderam enxergar um pouco do sofrimento que as mulheres vivenciam. Por mais que isso tenha sido comentando de forma exterior, isto é, não refletido como uma realidade que afetava a vivência de violência pessoal de cada um, sentimos que foi um passo importante para compreender algumas questões de gênero, pois não podemos pensar masculinidades sem refletir sobre aquilo que há no universo das mulheres.

Esse encontro fez com que refletíssemos que ao analisar episódios de violência contra mulher é necessário, além de repensar elementos da vida familiar ou conjugal, analisar a própria compreensão dos participantes sobre o que é violência e se eles percebem suas ações como tal. A forma relatada por alguns homens de resolução de problemas nas relações com suas companheiras, direcionava para a violência, pois havia muitas brigas com xingamentos e agressões verbais. Além disso, começamos a perceber que os homens,

Pê et al. (2022). Violência contra a mulher: experiência de profissionais facilitadores de um grupo reflexivo de homens. https://doi.org/10.32467/issn.2175-3628v23n1a8 
ao negarem a violência nas suas relações, não compreendiam o sofrimento desencadeado durante essas situações.

Identificamos a necessidade de encaminhamentos e orientações aos serviços que compõem a rede de atendimentos. Um dos participantes expôs como as dificuldades cotidianas o levaram ao uso abusivo de álcool e, posteriormente, como isso afetou seus relacionamentos com a família e amigos, tornando-se um movimento cíclico e intensificador dos problemas. A partir dessa fala, o participante foi convidado para atendimento individualizado e recebeu orientações sobre serviço especializado, no qual passou a ser assistido.

Ficou evidente a dificuldade em exercerem o autocuidado e o desconhecimento dos serviços disponíveis para atender suas necessidades. Nesse sentido, o grupo reflexivo é um espaço privilegiado para fortalecer a articulação em rede dos serviços de atendimentos, contribuindo para identificar demandas, acolher, orientar e encaminhar, visando garantir um atendimento integral.

Logo após a reunião, passamos a avaliar nossa vivência e planejar a próxima. Vimos que seria necessário trabalhar a consciência emocional no grupo, com vistas a ajudar os participantes a refletirem sobre a experiência de violência, sobre os seus comportamentos e sentimentos, bem como, sobre o que as suas companheiras ou ex-companheiras passaram. Destacando as dificuldades de um relacionamento conjugal, estimulando a reflexão sobre os problemas que viveram em suas relações afetivas.

\section{TERCEIRO ENCONTRO}

Iniciamos essa reunião com um momento de relaxamento por meio de técnicas de respiração e concentração, cujo objetivo foi promover o relaxamento físico e mental, a fim de trabalhar a consciência emocional. Em seguida, exibimos o vídeo Minha vida de João (Barker, 2001). O vídeo conta a história da construção da masculinidade do personagem João, desde sua infância até a vida adulta, tocando em vários pontos dessa construção: sexualidade, relacionamentos familiares e conjugais, trabalho, paternidade.

Logo após o vídeo, pedimos que eles refletissem em silêncio sobre sua história de vida, da infância até a vida adulta e, para tanto, utilizamos, nesse momento, a canção O homem também chora (Guerreiro menino) de Gonzaguinha (Gonzaguinha, 1994, faixa 11). Ao final da música, propusemos que eles compartilhassem os sentimentos surgidos durante esse momento e, caso desejassem, falassem sobre algum momento marcante de sua vida.

Os participantes aderiram à nossa proposta e falaram sobre momentos que marcaram a construção de sua masculinidade, e sobre o homem que se tornaram. Dois, em especial, nos chamaram a atenção: o primeiro falou que quando era criança viu a mãe sofrer muito por conta da violência do pai, isso provocou sofrimento e indignação nele e nos seus irmãos; o segundo contou que o pai maltratava muito ele, chegando a espancá-lo. Na adolescência começou a compreender mais as coisas e se rebelou contra o pai, que o expulsou de casa. A partir de então, trabalhou a vida inteira para poder sobreviver e por conta do processo judicial que estava submetido - por conta das medidas protetivas perdeu a casa que trabalhou para conquistar.

Esses relatos mostraram como as vivências negativas se tornaram um trauma e marcaram a construção subjetiva desses homens. O sofrimento imputado, desde cedo, e a

Pê et al. (2022). Violência contra a mulher: experiência de profissionais facilitadores de um grupo reflexivo de homens. https://doi.org/10.32467/issn.2175-3628v23n1a8 
violência perpetrada por alguém que deveria cuidar e proteger, é algo que nos impele, enquanto profissionais, a pensar a complexidade da violência de gênero que, na maioria das vezes, produz marcas potencialmente negativas para a vida das pessoas. Martínez-Moreno (2017), comenta que ao descrevermos, reconhecermos e reinterpretarmos os processos de violência que vivemos podemos aprender e delimitar tal experiência. O papel do facilitador seria permitir uma revisão localizada que proporcione essa delimitação da violência. Foi o que pudemos comprovar na nossa experiência, uma vez que os participantes do grupo, ao falarem da sua experiência de sofrimento, puderam reinterpretar o sofrimento vivenciado no passado e no agora. Daí a importância do espaço para fala.

Os homens falaram também sobre os conflitos vivenciados nos seus relacionamentos, muitas vezes, assim como o personagem de João (do vídeo exibido), não souberam como resolvê-los e, por isso, tornaram-se muito prejudiciais ao longo da vida. Por essa razão, ao final do encontro, no planejamento, decidimos promover um momento em que eles pudessem analisar e pensar as situações de conflitos que vivenciaram ou que poderiam vir a experienciar.

\section{QUARTO ENCONTRO}

Nesse encontro, propusemos a técnica do role playing proposta por Moreno (1993, 2014) que tem como fundamento a interpretação de papéis. O objetivo era trabalhar e repensar as formas de resolver conflitos durante uma relação afetiva com a parceira. Para tal, utilizamos o role playing como ferramenta para a geração de um conflito fictício no grupo. Ao planejarmos esse encontro, ficamos apreensivos em relação a como os homens iriam receber a atividade. Temíamos que ficassem inibidos e a participação fosse mínima. Entretanto, a maioria dos membros do grupo participou tentando resolver os conflitos, buscando solucioná-los.

Após explicar aspectos da técnica, iniciamos a atividade interpretando uma discussão de um casal que gerou um conflito. A psicóloga, facilitadora da técnica, durante o conflito pausou a cena interpretada e questionou os homens sobre o que deveria ser feito para resolver aquela situação. O primeiro homem que opinou foi convidado a trocar de lugar com a facilitadora e passou a interpretar junto com a assistente social. Esse movimento prosseguiu e os participantes do grupo puderam representar papéis diversos (homem e mulher, traidor e traído, violentador e vítima) e experimentar distintas formas de lidar com aquelas situações de conflito.

Naquele momento, que foi o ápice do grupo, vimos os homens participando ativamente, saindo das suas cadeiras, encenando, procurando formas de resolver as situações, expondo os próprios conflitos vivenciados outrora e, ao mesmo tempo, interagindo conosco e com os demais homens em busca de lidar com aquelas situações surgidas durante a atividade. Os homens expressaram seu entusiasmo com a técnica, mas perceberam que algumas situações são complicadas de resolver, porque "você não está só não relação", por isso "tem que ter muita paciência".

Ao final da atividade, um dos participantes falou que recebeu elogios da esposa, dizendo que o grupo estava ajudando a ele. Continuou afirmando que "viu melhoras em si em muitas coisas do dia a dia". Habka (2018), em um estudo sobre a experiência do homem acusado de violência doméstica participante de um grupo reflexivo, percebeu que esse

Pê et al. (2022). Violência contra a mulher: experiência de profissionais facilitadores de um grupo reflexivo de homens. https://doi.org/10.32467/issn.2175-3628v23n1a8 
espaço cria a possibilidade de desconstrução de crenças a respeito dos comportamentos que esperamos de homens e mulheres.

Esse modelo de intervenção, mesmo sendo um momento breve na vida de cada homem, pode ser uma ferramenta bastante eficaz, permitindo aos participantes e a nós mesmos - enquanto facilitadores - repensar as formas como agimos no cotidiano, nas nossas práticas de gênero, em nossos relacionamentos e na nossa prática profissional. Percebemos que as reflexões desencadeadas pelo grupo foram utilizadas pelos homens no seu dia a dia. Na experiência de Habka (2018), os homens conseguiram adotar novas práticas para situações de conflitos, valorizando principalmente o diálogo e a manifestação dos seus sentimentos. Alguns homens, do nosso grupo, também apontaram durante a técnica do role playing a necessidade de falar sobre o que sentiam e de repensar as formas como estavam resolvendo seus conflitos.

No planejamento do último encontro, decidimos apresentar a Lei Maria da Penha, pois os homens vinham questionando suas disposições e apresentando dúvidas em relação ao seu funcionamento prático. Moreira e Tomaz (2020) apontam a Lei Maria da Penha como tema essencial para formação no grupo reflexivo de homens, pois, apesar de cada grupo possuir uma metodologia distinta e específica, assuntos relativos à Lei são muito importantes no trabalho com homens acusados de violência contra mulheres.

\section{QUINTO ENCONTRO}

Iniciamos falando sobre o histórico da violência contra a mulher no Brasil e do contexto da promulgação da Lei Maria da Penha. Os homens mediante perguntas e reflexões sobre as disposições da Lei, demonstraram não terem conhecimento sobre os dados de violência contra a mulher, nem da dimensão do problema, o que contribui, a nosso ver, para a sua naturalização.

O segundo momento, dedicado à avaliação dos encontros, foi pautado no que chamamos de mural da mudança. A ideia foi fazer um mural no qual pudessem colocar o que fora aprendido nos encontros, além de escrever as mudanças percebidas a partir da experiência no grupo reflexivo. Para tanto, utilizamos a técnica de colagem para montar o mural.

Alguns homens escreveram, outros desenharam e recortaram. Depois que todos terminaram iniciamos uma conversa sobre o que fizemos. Um deles mostrou seu desenho, nele continha várias palavras, como "mudança", "paz", "futuro". Resumimos algumas falas para demonstrar as avaliações: "no começo, não sabia como iria ser, mas que hoje desejava que aquele grupo tivesse em todo lugar, se tivesse mais reuniões eu viria, pois gostei muito"; "a partir das nossas conversas, tinha repensado várias coisas"; "tinha repensado seu futuro e percebeu que gostaria bastante de retomar seu trabalho"; "um espaço como aquele, para falar de assuntos de homens, não existia na rua, por isso tinha gostado muito". Vários homens agradeceram à equipe, alguns agradeceram aos próprios participantes. No final, os homens se aplaudiram. Após esse momento, agradecemos a presença de todos, desejamos um futuro cheio de transformações positivas e encerramos o grupo.

Pê et al. (2022). Violência contra a mulher: experiência de profissionais facilitadores de um grupo reflexivo de homens. https://doi.org/10.32467/issn.2175-3628v23n1a8 


\section{CONSIDERAÇÕES FINAIS}

Percebemos que a experiência como facilitadores de um grupo reflexivo de homens além de nos possibilitar analisar e repensar vários aspectos da construção das masculinidades, nos impele a refletir sobre a necessidade de construir mais alternativas para trabalhar a temática da violência contra mulher. Diante dos vários desafios que esse fenômeno complexo nos apresenta, é possível pensar que o grupo reflexivo pode contribuir de forma direta para a vida não só dos homens (seu público-alvo), mas para a vida das mulheres. Essa estratégia propõe mudanças nas relações de gênero, visando ao combate à violência e à diminuição das desigualdades presentes nessas relações.

Constatamos que a produção de um espaço que possibilite a escuta e a transformação de homens acusados de violência contra mulher pode se tornar um fator decisivo no combate à violência contra mulher. Nossa experiência demonstrou que manter a agenda do grupo aberta, ou seja, planejar cada encontro a partir daquilo que foi trabalhado e discutido pelos participantes na reunião anterior foi fundamental para planejar e construir esse espaço de escuta. Dessa forma, por ser cada encontro elaborado a partir das falas dos homens e das demandas que traziam durante as reuniões, percebemos que essa metodologia contribuiu para adesão dos participantes nas atividades propostas e para participação ativa nas discussões dos temas.

No entanto, realizar esse planejamento do grupo reflexivo é um trabalho complexo, necessitando ser realizado por uma equipe multidisciplinar. É através da multidisciplinaridade que os saberes de todos os profissionais são agregados para que, durante a execução do grupo, os facilitadores possam manter uma escuta ativa das demandas que os homens trazem.

Os diferentes saberes dos profissionais e a forma como cada um enxerga o mesmo objeto permite pensar e/ou criar intervenções que se adaptem melhor às particularidades dos participantes. Dessa forma, através de múltiplas intervenções podemos propor novas alternativas para entender e combater a violência contra a mulher objetivando também possibilitar mudanças positivas na vida desses homens.

Vale destacar que a o trabalho com grupos reflexivos nos Juizados são estruturados a partir de uma rede constituída como uma política pública. O Juizado funciona em conjunto com outras esferas sejam elas jurídicas, de saúde, ou de assistência social, o que é essencial para ofertar, em caso de necessidade, serviços da rede pública para os participantes e atuar, de forma conjunta, no enfretamento da violência contra mulher.

Como dito anteriormente, o método utilizado nesse estudo tem um enfoque construtivista-narrativista com perspectiva de gênero, baseado na metodologia proposta por Beiras e Bronz (2016). Contudo, essa metodologia foi adaptada pelo Juizado a fim de contemplar a alta demanda da instituição. Dessa forma, a principal adaptação se deu em relação ao número de encontros, diminuindo de doze para cinco. Compreendemos que se houvesse a possibilidade de realizar mais encontros poderíamos trabalhar melhor as questões individuais durante o processo grupal.

No entanto, apesar do número reduzido de encontros, avaliamos que os resultados obtidos foram bastantes positivos. Apontamos que a adesão foi bastante significativa, visto que os homens participaram ativamente desde o primeiro encontro até o último, o que pode

Pê et al. (2022). Violência contra a mulher: experiência de profissionais facilitadores de um grupo reflexivo de homens. https://doi.org/10.32467/issn.2175-3628v23n1a8 
ser identificado como reflexo de que os homens visualizando o tempo de duração do processo do grupo reflexivo se esforçaram para melhor aproveitar o espaço que foi ofertado.

Por fim, esse relato de experiência possibilita refletir sobre alguns desafios que os profissionais podem enfrentar ao trabalhar a temática da violência contra mulher, pois cada homem tem uma história única em relação à violência que foi acusado de cometer. Por esse motivo, verifica-se a importância de novos estudos e pesquisas que contemplem o método do grupo reflexivo, a fim de analisar outras formas possíveis de trabalhar a temática da violência contra mulher e pensar o papel que a construção das masculinidades desempenha na manutenção dessa violência. Esse relato nos provoca, ainda, a pensar que a experiência profissional com grupos reflexivos de homens é uma iniciativa recente na história do Brasil e, por esse motivo, necessita ser estudada de forma mais aprofundada, observando, especialmente, as diversas possibilidades que tal prática pode oferecer.

\section{REFERÊNCIAS}

Aguiar, L. H. M. D. (2009). Gênero e masculinidades: Follow-up de uma intervenção com homens autores de violência conjugal. (Dissertação de Mestrado), Universidade de Brasília. https://repositorio.unb.br/handle/10482/8188

Antezana, A. P. (2012). Intervenção com homens que praticam violência contra seus cônjuges: Reformulações teórico-conceituais para uma proposta de intervenção construtivista-narrativista com perspectiva de gênero. Nova Perspectiva Sistêmica, 21(42), 9-27. https://doi.org/10.38034/nps.v21i42.121

Barker, G. (2001). [I Papai]. (23 de julho de 2017). Minha vida de João [Arquivo de vídeo]. YouTube. https://www.youtube.com/watch?v=43iadIjzLLI

Beiras, A., \& Bronz, A. (2016). Metodologia de grupos reflexivos de gênero. Instituto Noos.

Beiras, A., Martins D. F., \& Hugill, M. S. G. (2020). Mapeamento nacional das iniciativas, programas ou grupos para homens autores de violência contra mulheres. (Período: 87-2020 a 9-10-2020). UFSC Margens. Disponível em: https://margens.ufsc.br/publicacoes-tecnicas/mapeamento-nacional-das-iniciativasprogramas-ou-grupos-para-autores-de-violencia-contra-mulheres/

Bortoli, R., \& Zucco, L. (2016). Homens autores de violências de gênero contra a mulher: o relato de uma experiência profissional. In A. M. Veiga, T. K. Lisboa, \& C. S. Wolff (Orgs.), Gênero e violências: Diálogos interdisciplinares (pp. 181-201). Editora do Bosque. Disponível em: https://repositorio.ufsc.br/xmlui/handle/123456789/171684

Cerqueira, D. R. D. C. C., Bueno, S. C., Alves, P. P., Lima, R. S. D., Silva, E. R. A. D., Ferreira, H. R. S. A., ... \& Figueiredo, T. D. S. (2020). Atlas da violência 2020. Instituto de Pesquisa Econômica Aplicada. https://dx.doi.org/10.38116/riatlasdaviolencia2020

Connell, R. (1995). Políticas de Masculinidade. Educação e Realidade, 20(2), 185-206. Disponível

em: https://www.seer.ufrgs.br/educacaoerealidade/article/viewFile/71725/40671

Pê et al. (2022). Violência contra a mulher: experiência de profissionais facilitadores de um grupo reflexivo de homens. https://doi.org/10.32467/issn.2175-3628v23n1a8 
Fórum Brasileiro de Segurança Pública. (2020). Violência doméstica durante a pandemia de Covid-19. Nota técnica. Disponível em: https://forumseguranca.org.br/publicacoes_posts/violencia-domestica-durantepandemia-de-covid-19/

Gonzaguinha. (1994). Um homem também chora (Guerreiro Menino) [música]. In Meus momentos. EMI Music Brasil.

Granja, E., \& Medrado, B. (2009). Homens, violência de gênero e atenção integral em saúde. Psicologia \& Sociedade,21(1), 25-34. https://doi.org/10.1590/S010271822009000100004

Gutiérrez, E. J. D. (2015). Códigos de masculinidad hegemónica en educación. Revista Ibero-americana de Educação, 68, 79-98. https://doi.org/10.35362/rie680201

Habka, I. D. C. (2018). A experiência do homem acusado de violência doméstica que participou de um grupo reflexivo para homens à luz da Gestalt-terapia [Monografia], Centro Universitário de Brasília. Disponível em: https://repositorio.uniceub.br/jspui/handle/235/11471

Lei $\mathrm{n}^{\circ} .11 .340$ de 2006. (2006). Cria mecanismos para coibir a violência doméstica e familiar contra a mulher, nos termos do $\S 8^{\circ}$ do art. 226 da Constituição Federal, da Convenção sobre a Eliminação de Todas as Formas de Discriminação contra as Mulheres e da Convenção Interamericana para Prevenir, Punir e Erradicar a Violência contra a Mulher; dispõe sobre a criação dos Juizados de Violência Doméstica e Familiar contra a Mulher; altera o Código de Processo Penal, o Código Penal e a Lei de Execução Penal; e dá outras providências. 07 de agosto de 2006. ADI $\mathrm{n}^{\circ} 4424$.

Lima, M. L. C. (2008). Homens no cenário da Lei Maria da Penha: Entre (des) naturalizações, punições e subversões. (Dissertação de Mestrado), Faculdade de Psicologia, Universidade Federal do Pará. Disponível em: http://repositorio.ufpa.br/jspui/handle/2011/5128

Lima, V. H. B. (2019). Produção de sentido em um grupo reflexivo para homens autores de violência. (Dissertação de Mestrado), Universidade Federal do Rio Grande do Norte. Disponível em: https://repositorio.ufrn.br/jspui/handle/123456789/26670

Martínez-Moreno, M. J. (2017). O duplo registro do gênero dos facilitadores de grupos reflexivos para homens autores de violência. In A. Beiras, \& M. Nascimento (Orgs.), Homens e violência contra mulheres. Pesquisas e intervenções no contexto brasileiro (pp. 169-192). Instituto Noos.

Medrado, B., Lemos, A. R., \& Brasilino, J. (2011). Violência de gênero: Paradoxos na atenção a homens. Psicologia em Estudo, 16(3), 471-478. http://dx.doi.org/10.1590/S0102-71822009000100004

Moreira, K. S., \& Tomaz, R. S. R. (2020). Grupo reflexivo: Um relato de experiência sobre uma estratégia de enfrentamento contra a violência doméstica. Brazilian Journal of Development, 6(12), 98700-98715. https://doi.org/10.34117/bjdv6n12-382

Moreno, J. L. (2003). Psicodrama. (9a ed.). Cultrix.

Moreno, J. L., \& Moreno, Z. T. (2014). Fundamentos do psicodrama. Agora.

Scott, J. (1995). Gênero: uma categoria útil de análise histórica. Educação \& Realidade, 20(2), 71-99. Disponível em: https://www.seer.ufrgs.br/educacaoerealidade/article/viewFile/71721/40667

Pê et al. (2022). Violência contra a mulher: experiência de profissionais facilitadores de um grupo reflexivo de homens. https://doi.org/10.32467/issn.2175-3628v23n1a8 
Thürler, D., \& Medrado, B. (2020). Masculinidades contemporâneas em disputa. Revista Periódicus, 1(13), 1-8.

Submetido: $27 / 03 / 2021$

Reformulado: 05/05/2021

Aceito: $12 / 05 / 2021$

\section{Sobre os autores:}

Felipe Zeferino Pê é psicólogo e Mestre em Psicologia da Saúde pela Universidade Estadual da Paraíba.

Railda Sabino Fernandes Alves é docente do Programa de Pós-graduação em Psicologia da Saúde da Universidade Estadual da Paraíba.

Clarissa Paranhos Guedes é psicóloga do Juizado de Violência Doméstica e Familiar Contra Mulher de Campina Grande-PB.

Marceane de Azevedo Silva é assistente social do Juizado de Violência Doméstica e Familiar Contra Mulher de Campina Grande-PB.

Marcia Batista Bastos é psicóloga do Juizado de Violência Doméstica e Familiar Contra Mulher de Campina Grande-PB.

Correspondência: felipezpe9@gmail.com 